\title{
O ENVOLVIMENTO PARENTAL NAS INSTITUIÇÕES DE EDUCAÇÃO INFANTIL*
}

\author{
Sara Lúcia G. Ferreira ${ }^{1}$ \\ Márcia Andréia Triches ${ }^{2}$
}

Resumo: Este artigo apresenta uma reflexão sobre o envolvimento parental na instituição educativa. A relação entre a família e a instituição de educação infantil é analisada, focando vantagens e constrangimentos, modalidades de trabalho, competências educativas e estratégias de envolvimento da família. As condições necessárias para que esta relação seja um fator de desenvolvimento das crianças, das instituições de educação infantil e das famílias são também identificadas a partir da literatura.

Palavras-chave: envolvimento parental, instituição de educação infantil, crianças. 


\section{Introdução}

Historicamente, a instituição de educação infantil surge como uma extensão da família, sendo uma das suas funções alargar e complementar o papel educativo. Principalmente a partir do século XX, psicólogos, antropólogos, sociólogos e pedagogos passaram a focar e a analisar o envolvimento parental, seus determinantes e suas consequências, desenvolvendo teorias (SARMENTO, 2005; HOMEM, 2002).

A relação família-instituição de educação infantil é uma realidade existente em todas as instituições, ainda que, a sua efetivação em termos de envolvimento não aconteça em todas na mesma escala.

O envolvimento dos pais, especificadamente, na dimensão da educação infantil, apresenta tradições diferentes em países distintos. Apesar dessa demarcação, as disposições pedagógicas convergem no mesmo entendimento de que a aprendizagem das crianças de pouca idade está muito enraizada na sua vida quotidiana, nas suas experiências e vivências.

\section{Vantagens e constrangimentos}

Estudos sobre as relações entre a instituição e a família reforçam a argumentação dos benefícios que esse envolvimento representa para as crianças (melhoram o seu desempenho/aproveitamento), pelos professores que recebem mais apoio e reconhecimento social, e pelas famílias que passam a conhecer melhor o processo educativo de seus filhos (DAVIES, MARQUES e SILVA, 1993).

Há também estudos que demonstram que esses benefícios são mais facilmente percebidos nas famílias das classes média e alta, explicando o menor envolvimento das famílias das classes mais desfavorecidas pelo seu distanciamento da cultura escolar. Contudo, nem todas as famílias e nem todas as crianças obtêm os mesmos benefícios ou são favorecidos de forma equitativa pelo envolvimento parental nas instituições educativas (SILVA 1996 e 2003).

Por outro lado, há ainda, estudos que apresentam dados complementares que desmentem que todas as práticas de envolvimento 
parental nas instituições produziram impactos positivos no desempenho das crianças (MARQUES, 1998). Estudos estes que também revelam alguma promiscuidade dos pais provenientes das classes média e alta na maioria das associações de pais, por utilizarem, pontualmente, o seu poder de participação na tomada de decisões a favor dos seus próprios filhos, dificultando, dessa forma, alterações na estrutura e nas práticas das instituições e preservando - ou até acentuando mais as desigualdades culturais existentes (SILVA, 2003).

O envolvimento parental nas instituições educativas pode provocar efeitos perversos se, na sua implementação, as instituições não tiverem a preocupação de responder às necessidades educativas das classes mais desfavorecidas. Caso não haja um cuidado de conceber soluções para que as crianças das famílias de rendimentos mais baixos possam igualmente colher proveitos, a instituição pode estar a demarcar as diferenças e os desequilíbrios, ao invés de estar a promover o sucesso educativo das crianças atendidas.

Algumas instituições questionam a legitimidade da pressão que é exercida pelos pais nas práticas pedagógicas, defendendo que a área pedagógica exclusivamente técnica prende-se com a atribuição da autonomia do professor. Questões como essas esbarraram no conceito de parceria educativa e nos limites da atuação comum. O alcance da noção de parceria inclui várias formas de práticas, de comunicação, de participação nos órgãos da instituição, de colaboração em atividades educativas fora da sala, de colaboração em atividades educativas dentro da sala, de apoio ao estudo, em casa e outras. No entanto, aceitam-se os benefícios das práticas de comunicação, de colaboração em atividades educativas fora da sala de aula.

Os problemas levantados não impedem que se reconheçam os benefícios resultantes de bons programas de envolvimento parental. Parece, pois, ser possível desenvolver programas de envolvimento parental dirigidos às famílias mais afastadas da cultura escolar, gerando benefícios ao nível do desempenho e da integração de todos. Entretanto, a desarticulação ou a falta de coerência entre as políticas para a infância e a sua própria aplicação incorrem no risco de insistir numa tendência em que as crianças de famílias com menos recursos recebam serviços educativos de menor qualidade. 


\section{Modalidades de trabalho}

São vários os níveis e concepções que perspectivam a participação ${ }^{3}$ parental nos contextos de educação infantil, detectados nos modelos pedagógicos descritos ou sintetizados em quatro fases distintas: i) como receptores de informação sobre o que acontece na instituição (utilizamse os meios de comunicação habituais: recados, trabalhos para casa, conversas e contatos nos momentos da chegada e da saída); ii) alunos de cursos de educação parental (ações de formação onde é desenvolvida a discussão em grupo, a observação de casos, treino de aptidões ou aconselhamento individualizado); iii) voluntários participantes - (acompanhamento do programa educativo com os professores altamente motivados na realização das atividades com outros pais; iv) co-gestores - envolvidos - (participam na orientação pedagógica, na organização administrativa e na administração financeira das instituições de educação infantil).

A autora Fontao (2000) elege três modalidades de relações entre pais e professores, sendo cada uma delas, legitimada por um grupo diferente de objetivos, pressupostos, atitudes, comportamentos e formas de trabalho. Para desenvolver uma visão de mudança é preciso reconhecer que há diferentes maneiras de envolver os pais na educação dos seus filhos. Intervir significa tomar parte e não simplesmente exigir, controlar, protestar. As três modalidades apresentadas por Fontao são:

- Tutorial - tem como principal objetivo diminuir o conflito entre pais e professores principalmente através da natural diferenciação de funções, pautado em três pressupostos: os pais delegam à escola a responsabilidade de educar os seus filhos; os professores aceitam esta delegação de responsabilidade; os pais preocupam-se com os resultados educativos.

- Colaborativa - permite o envolvimento de um grande número de pais. Trata-se de conseguir que o currículo seja mais conciso ao incorporar os pontos de vista, valores, conhecimentos das famílias representadas na instituição de educação infantil. A lógica desta modalidade observa: a continuidade da aprendizagem entre a casa e a instituição de educação infantil, de modo a desenvolver coerentemente a personalidade das crianças; o aumento da motivação, entusiasmo e 
maturidade das crianças, ao desenvolver as suas aprendizagens com harmonia; a disposição de mais recursos (humanos e materiais) que permitam levar a cabo o trabalho educativo com maior eficácia.

- Co-participativa - dá ênfase à comunicação bidirecional, à força e apoio dos pais e à resolução de problemas, conjuntamente com os professores. A mesma pauta-se em dois pressupostos importantes: o primeiro requer a reflexão sobre a própria atividade educativa, pois trata-se de descobrir novos papéis, práticas, relações e atitudes que permitam uma melhoria da realidade escolar; o segundo pressuposto exige a colaboração entre pais e professores, pois nenhum destes grupos deve trabalhar isoladamente.

McAllister (1993) define quatro elementos importantes para a interação parental - família e instituição educativa: criar uma comunicação bidirecional; melhorar a aprendizagem tanto na escola como em casa; proporcionar apoio mútuo (os professores auxiliam os pais oferecendo-lhes programas educativos que respondem aos seus interesses e necessidades); e, por fim, tomar decisões conjuntas (os pais e os professores trabalham juntos para melhorar a instituição de educação infantil através da participação em conselhos e grupos de direção e planejamento). O importante é, então, captar o sentido educativo da relação com as crianças, adquirir uma nova sensibilidade e um novo estilo de interação.

A realização de oficinas pedagógicas, por exemplo, permitirá a integração dos pais na tarefa educativa, conhecendo de forma prática o trabalho que se realiza e proporcionando um clima de convivência, liberdade e espontaneidade, o que garante o desenvolvimento natural das relações entre a família e a instituição de educação infantil.

No mesmo sentido, Fontao (2000) defende que a participação dos pais no planejamento educativo foi e continua sendo considerada como um critério de qualidade, tal como uma garantia de eficácia da ação educativa desenvolvida. Em muitas instituições educacionais, a Associação de Pais constitui um dos pilares da participação ativa e organizada dos pais. A presença dos pais nas reuniões e a defesa dos representantes por eles eleitos têm, em muitos lugares, uma grande importância social. Numa instituição de educação infantil, o projeto educativo estabelece o conjunto de procedimentos e orientações que 
determinam a sua organização, programação e gestão. Nessa dimensão, os pais poderão participar no referido diploma destacando, por exemplo, as situações que não respeitem os princípios constitucionais exigindo desse modo, o seu cumprimento.

O envolvimento parental pode ir mais além. Segundo Katz et al. (1997), os pais podem envolver-se mesmo a nível metodológico, no trabalho de projeto(s), pelo menos, de quatro formas: na primeira, os pais e as crianças podem partilhar facilmente informações sobre os projetos porque é provável que os tópicos lhes sejam familiares; na segunda, os pais podem ser incentivados a perguntar aos filhos como está o projeto a progredir e quais as atividades que estão sendo desenvolvidas; na terceira, os pais podem ser "muito úteis" na recolha de informações, de gravuras, de livros e de objetos que ajudem toda a turma na busca de conhecimentos sobre o tópico; na quarta, num estágio mais avançado do projeto, convidar os pais a comparecer na instituição e ver o trabalho que as crianças estão realizando. Assim, os pais se sentirão incluídos numa parte importante da educação dos seus filhos.

A base de uma boa relação entre a família e a instituição educativa começa com uma boa colaboração a nível da informação. Visto que os mais pequenos necessitam da companhia dos adultos para chegarem à instituição educativa, esta circunstância propicia um contato diário entre a mãe ou o pai e o professor. Estes momentos podem ser aproveitados para trocar informações de tipo informal. As sessões de informação são a base de participação para os pais, pois os mantêm informados do conteúdo e das possibilidades efetivas de colaboração. Todos os pais em geral, e não só os que são os seus representantes nas estruturas participativas, são, identicamente, encorajados a conhecer e integrar os valores e atitudes que a instituição educativa promove, através das atividades educativas diária.

Ainda segundo Brickman \& Taylor (1991), para obter uma eficaz participação dos pais é preciso definir os objetivos, para então organizar um programa de participação dos mesmos, o primeiro passo deverá consistir em estabelecer os objetivos à luz das necessidades dos professores e das famílias, para os quais será definido, pelo menos, um objetivo mais específico relativamente à participação dos pais; $\mathrm{O}$ segundo passo é organizar as atividades. Nesta fase, organizam-se 
duas ou três atividades para cada um dos objetivos fixados anteriormente. Qualquer que seja a estratégia assumida, será necessário escolher atividades que se ajustem às situações das crianças e respectivas das famílias. Na sequência deverá ser feito o balanço, ou seja, ao fim de alguns meses, recomenda-se que sejam passadas em revista as atividades de participação dos pais e avaliados os resultados. O momento final será para fazer ajustes, pois, à medida que o tempo passa, vai sendo necessário reavaliar e ajustar as atividades que se destinam a obter e estimular a maior participação dos pais no contexto formal de educação.

\section{Competências educativas}

Sendo constatada que a qualidade das relações parentais tem um importante papel, principalmente na adaptação e aceitação da criança no contex to educativo, justifica-se, então, um particular cuidado em estabelecer um bom relacionamento com os seus familiares, no sentido de permitir à criança, quando chega à creche e à pré-escola, seguir uma trajetória mais positiva. Aos pais, pode ser sugerido que colaborem com o professor de modo efetivo: 1 - transferir autoconfiança, despedindo-se da criança com um gesto carinhoso; 2 conversar diariamente com a criança sobre como correu o dia; 3 garantir à criança uma dieta equilibrada; 4 - garantir que ela tenha onde ficar se adoecer; 5 - preparar em casa um lugar ou um tempo calmo para atividades que exijam atenção ou concentração; 6 - mostrar a sua própria curiosidade, respeitando as suas perguntas e os seus esforços; 7 - incentivar a leitura e o contato com livros (em casa ou na biblioteca) nos períodos calmos; 8 - ser um aliado do professor (não manter conversas sobre a criança e evitar criticá-lo na sua presença); 9 - organizar as atividade diárias com a criança (material, muchilas, atividades); 10 - declarar-lhe que é importante (saber-se amada, tornaa mais amável com os outros) (Baseado em Doe Mimi, 2008).

A estratégia de intervenção e formação parental ou familiar parecem ter identicamente sentido, sendo que o principal destaque é à sensibilização (da sociedade em geral, mas dos pais em particular) 
para o valor social do seu papel na educação dos filhos, para uma maior compreensão do processo de desenvolvimento infantil e para a diminuição do stress, mais frequente no período da separação. Uma conscientização progressiva tem em vista o seu próprio equilíbrio e, consequentemente, a estabilidade emocional das crianças, o que contribui, substancialmente, para a melhoria das relações dentro da família.

Ao abordar a qualidade dos contextos oferecidos à criança, é impossível não referenciar as teses de Bronfenbrenner (1979, 1996; PORTUGAL, 1992 e 1994), segundo as quais o desenvolvimento e bem-estar da criança, nos planos intelectual, social e emocional, demandam a participação regular e contínua da criança, em atividades recíprocas, progressivamente mais complexas, com uma ou mais pessoas com quem a criança desenvolva uma forte ligação afetiva responsiva, irracional (desempenhando, assim, um importante papel no bem-estar e desenvolvimento da criança), de preferência ao longo de toda a sua vida.

Ao serem avaliados, os efeitos da frequência em instituições de educação infantil têm impactos no desenvolvimento da criança. A complexa ecologia do desenvolvimento humano deve ser considerada tendo em atenção, principalmente, as características familiares e os contextos de acolhimento das crianças. A qualidade dos contextos familiares e da instituição educativa tem múltiplas influências; as acumulações de tensões econômicas, sociais e psicológicas podem afetar a qualidade dos cuidados a oferecer à criança. Torna-se necessário desenvolver uma melhor compreensão de equilíbrio entre fatores de risco e fatores protetores. A elaboração e manutenção de esquemas de interação progressivamente mais complexos, a ligação afetiva entre os responsáveis pela educação da criança, e a própria criança dependem também da disponibilidade e envolvimento de terceiras pessoas que encorajam, estimulam, dão estatuto e expressam a sua admiração e afeto à pessoa que se ocupa da criança e com quem realiza atividades conjuntas.

Bronfenbrenner (1979; 1996), no seu modelo ecológico do desenvolvimento humano, tem sido útil na orientação de estudos empíricos, relacionados com fatores complexos que afetam as interações entre pais e filhos, na medida em que considera não só as 
ligações, quer com o sistema informal (círculo de amigos, membros da família alargada), quer com o formal (organizações da comunidade, organismos governamentais, instituições educacionais), mas, também, a influência significativa que podem exercer no seu comportamento e, consequentemente, na sua interação com os filhos. Segundo Spodek (2002, pp. 761-787), as interações dos pais com os filhos são influenciadas por uma diversidade de fatores sobrepostos, entre eles o comportamento e as características dos filhos, os juízos dos pais sobre os objetivos da socialização, as suas convicções, valores e modelos internos de funcionamento parental, o contexto familiar e social e o comportamento das outras pessoas nesse contexto.

O envolvimento dos pais na educação desenvolvida na instituição de educação infantil é crucial, uma vez que ela afeta tanto o comportamento dos pais como o desenvolvimento e a educação das crianças. Estudos nesta área sugerem várias conclusões acerca da influência dos pais: os seus conhecimentos relativamente ao desenvolvimento das crianças permitem-lhes apoiar o filho na adaptação ao ambiente (nas atividades e nas expectativas); a percepção dos pais sobre os fatores que afetam o desenvolvimento das crianças e as suas convicções acerca da sua própria influência sobre os filhos, podem ser ainda mais influentes do que o seu conhecimento acerca do desenvolvimento do filho; as práticas de educação são influenciadas pela índole de atuação dos pais, pelo temperamento da criança, pelas variáveis demográficas, pela cultura e etnia familiares (FERREIRA, s/d).

Os benefícios a nível da aprendizagem das crianças, a nível do trabalho dos profissionais de educação e a nível das famílias, têm sido apontados em diversos estudos. Referenciamos aqui, em especial, Homem (2002), que concluiu em seus estudos que a confiança na instituição e no seu pessoal são o alicerce por primazia para a construção da participação dos pais; que a superficialidade das relações entre pais e profissionais e a marginalização dos primeiros, bem como a busca empenhada de apoios por parte dos professores e, ainda, a desvalorização dos pais como parceiros educativos, são aspectos que abrem caminho a uma intervenção parental reservada e convergente. A forma como os pais participam está diretamente ligada ao entendimento das perspectivas do pessoal quanto a essa participação. 
Para a concretização de uma participação mais ativa e decisória por parte de todos os pais, considera-se necessário que os professores de educação infantil encontrem, nas relações com os pais, um equilíbrio, entre o formal e o informal, diversifiquem as estratégias de participação dos pais, intencionalizem essas estratégias e se mobilizem profissionalmente (e mobilizem os pais) para a discussão, para aceitação da divergência e, assim, para a parceria e para a experiência da cidadania. Em suma, impera uma participação enquanto exercício de cidadania ativa na intervenção no mundo, através da análise constante da realidade e de uma ação cada vez mais consciente sobre ela.

A relação entre uma criança e um adulto é uma relação entre dois seres humanos, com experiências de vida diferentes, com graus de maturidade diversos, com perspectivas e visões discrepantes sobre o mundo, a influência que estas circunstâncias podem ter na vida dos mesmos difere em cada contexto de vida. As características familiares, da criança e do contexto em que a relação se desenvolve influenciam diferentes atitudes e estilos educativos (SARMENTO, 2005).

O comportamento parental é influenciado pelas contribuições únicas de cada um, evidenciadas nas características de personalidade, capacidades, nível de maturidade, valores e crenças educativas. Da compreensão do contributo de cada adulto para a situação educativa decorre a necessidade de considerar as histórias de vida de cada um, na medida em que, no decurso das suas vidas, os pais desenvolvem determinados estilos interativos, maneiras de lidar com situações mais ou menos difíceis, estilos de resolução de problemas que os influenciarão no desempenho das suas funções parentais.

As características do contexto, tanto imediato como o mais remoto, influenciam as características e comportamentos parentais. Por exemplo, a qualidade da relação conjugal, pode influenciar o bemestar psicológico dos pais e afetar os seus comportamentos relativamente às crianças. Neste caso, os membros das redes sociais parentais podem fornecer apoio emocional aos pais e informações útil para o desempenho das responsabilidades educativas ou, pelo contrário, podem constituir fontes de tensão para os pais.

Características do contexto mais vasto, como o ambiente socioeconómico, influenciam o grau de tensão experienciadas pelos 
pais e, consequentemente, o modo como os pais se relacionam com os filhos. As características familiares, que parecem proteger mais a criança, dizem respeito a uma boa relação com, pelo menos, uma figura parental. Crianças com uma boa relação com pelo menos uma figura adulta têm menos possibilidade de desenvolver perturbações que outras crianças, em ambientes familiares semelhantes. Mesmo nas piores circunstâncias familiares, alguns fatores podem equilibrar as influências de um mau processo adaptativo e, como tal, perturbadoras. Os fatores protetores externos ao lar incluem as instituições educativas da criança, nomeadamente, a creche e a pré-escola de boa qualidade.

\section{Estratégias de envolvimento}

Uma boa relação entre a família e a instituição apoia-se numa boa colaboração a nível da comunicação e da informação (FONTAO, 2000). Esta troca de informação pode desenvolver-se através de estratégias muito elementares: nos encontros diários, fundamentais para compreender o estado de espírito ou comportamentos pontuais da criança, nas reuniões onde é concedida informação para todos os pais ou na elaboração de registos individuais sobre a evolução das crianças.

As ações educativas não devem ser reduzidas somente às crianças. Deve também aproveitar os conhecimentos e vivências dos pais, por exemplo, trazendo para o presente todas as tradições educativas que estavam um pouco esquecidas e que podem ser recuperadas e transformadas em verdadeiras fontes de conhecimento. O professor poderá também promover pequenas reuniões entre os pais em que os adultos possam discutir temas pedagógicos, na área da psicologia e temas sociais variados, exercendo assim o exercício da troca e da aprendizagem, uns com os outros (FONTAO, 2000).

Em síntese, o professor deve ter presente que não existem fórmulas ou receitas exclusivas, mas diferentes maneiras de envolver os pais na educação dos seus filhos. Antes de iniciar um trabalho de cooperação entre pais e professores, será, sempre necessário conhecer como cada grupo percepciona o outro, as realidades sociais e pessoais que existem e o contexto onde estão inseridos. Os pais parecem 
entender cada vez mais que intervir não significa somente exigir, controlar e protestar, mas sim tomar parte nas decisões, nas responsabilidades e, ao mesmo tempo, ajudar e colaborar nas atividades desenvolvidas, quer apoiando, quer disponibilizando meios ou materiais. A seguir apresentamos de forma esquemática, algumas das estratégias mais referenciadas e significativas que a revisão teorética produziu:

\begin{tabular}{|l|l|}
\hline \multicolumn{1}{|c|}{ AÇÃO } & \multicolumn{1}{c|}{ ATUAÇÃO DO PROFESSOR } \\
\hline $\begin{array}{l}\text { Cuidado no período de } \\
\text { integração }\end{array}$ & $\begin{array}{l}\text { Permitir a presença dos pais na sala durante um período até } \\
\text { que a criança se ambiente. }\end{array}$ \\
\hline $\begin{array}{l}\text { Organização de oficinas } \\
\text { pedagógicas entre pais e } \\
\text { filhos e entre pais e pais }\end{array}$ & $\begin{array}{l}\text { Exemplos de trabalhos - pais vs. crianças: culinária, pintura, } \\
\text { contos, trabalho em papel, música, etc. } \\
\text { Exemplos de trabalhos - pais: elaboração de material didático } \\
\text { para as salas, colaboração na decoração e organização de } \\
\text { festas, colaboração em atividades extra escolares e } \\
\text { participação na realização de revistas, jornais ou outros } \\
\text { projetos da instituição de educação infantil. }\end{array}$ \\
\hline $\begin{array}{l}\text { Formação parental através } \\
\text { da criação de grupos de } \\
\text { discussão e debate ou } \\
\text { fóruns }\end{array}$ & $\begin{array}{l}\text { Esclarecimentos, sensibilização e conscientização sobre a } \\
\text { importância de determinados assuntos e seus consequentes } \\
\text { reforços no ambiente familiar, (exemplo: na área da saúde } \\
\text { sobre vacinação, prevenção de acidentes e primeiros socorros, } \\
\text { alimentação, higiene, doenças transmissíveis). }\end{array}$ \\
\hline $\begin{array}{l}\text { Fichas (trabalhos) para } \\
\text { casa }\end{array}$ & $\begin{array}{l}\text { Troca de informação de forma a prolongar o trabalho } \\
\text { desenvolvido na instituição em casa (exemplo: da autonomia } \\
\text { pessoal e social). }\end{array}$ \\
\hline $\begin{array}{l}\text { Placards, mural de parede } \\
\text { e registos escritos }\end{array}$ & $\begin{array}{l}\text { Elaboração de um quadro informativo e formativo na entrada } \\
\text { da instituição onde podem também ser registadas sugestões ou } \\
\text { dúvidas. }\end{array}$ \\
\hline $\begin{array}{l}\text { Cartas, correspondências, } \\
\text { recados ou notícias }\end{array}$ & $\begin{array}{l}\text { Informações regulares sobre o que a criança fez durante o dia } \\
\text { ilustradas pela mesma, relatando experiências positivas ou os } \\
\text { momentos mais significativos. }\end{array}$ \\
\hline Comunicações orais & $\begin{array}{l}\text { Reuniões e conversas informais nos momentos do acolhimento } \\
\text { e da despedida. }\end{array}$ \\
\hline
\end{tabular}

Conforme exposto, é preciso construir co-responsabilidades, desenvolver um trabalho conjunto, envolvendo todos. O envolvimento parental não pode ser limitado apenas a orientações, informações e esclarecimentos, mas para uma pró-atividade permanente - para o bom desenvolvimento da criança da instituição de educação infantil e da família (TRICHES, 2008). 


\section{Considerações finais}

Não existe uma receita única, pronta, nem tão pouco caminhos já definidos para resolver as questões do envolvimento e das relações entre as instituições de educação infantil e as famílias. O que existe são desafios e possibilidades: desafios que são múltiplos e possibilidades que são inúmeras, vinculadas sempre ao contexto em que a instituição e a família estão inseridas, uma vez que as práticas educativas parentais são diferentes e dependem de muitos fatores, contextos e situações.

Portanto, a educação não resulta apenas do que se aprende na instituição educativa, mas do que se aprende igualmente na família, em casa e na sociedade. Ao professor cabe a responsabilidade de demonstrar que é possível, quer desenvolver metodologias de intervenção ou de educação parental respeitadoras, quer acompanhar a família no processo de descoberta (ou criação) de significações múltiplas sobre o seu papel no processo educativo. É imprescindível que o fortalecimento das relações entre a instituição educativa e as famílias façam parte do currículo, que seja um eixo de sustentação das propostas do mesmo, e que o mesmo seja discutido e estudado por todos os envolvidos inclusive a família. É uma tarefa conjunta, de todos e de cada um.

A parceria entre as instituições de educação infantil e os pais é fundamental, no sentido em que estes poderão ter um maior conhecimento, não só do trabalho realizado, como também do processo educativo dos seus filhos. O envolvimento parental não se constrói de uma forma padronizada. O delineamento das estratégias com vista à promoção do envolvimento parental precisa ser construído com base no conhecimento das famílias. Conforme já referimos não há um conjunto de parâmetros previamente definidos. Escola e família têm que comunicar e desenvolver um esforço convergente ao nível das atitudes, ideias e percepções sobre a educação de infância e sobre o envolvimento parental, mas também convergir relativamente à definição dos respectivos papéis e funções.

Considerando que a iniciativa para a participação e inclusão dos pais deverá surgir da escola e partindo de uma base consciente da necessidade do envolvimento da família e dos benefícios que daí 
decorrem, os profissionais da educação infantil devem aproximar-se da família e desenvolvem assim uma relação estreita, transformando esta interação numa mais-valia para as crianças, para a família e para a instituição infantil. A sua efetivação depende claramente das instituições, isto é, do modo como os professores estão abertos a colaborar com os pais.

As instituições de educação infantil não têm que desenvolver uma ideia e vendê-la aos pais, e estes, por seu turno, não têm apenas que informar os profissionais acerca do "mundo real" no qual se propõe que eles não vivam. Se os pais perceberem que sua participação tem resultados palpáveis em termos de influência na instituição é que eles se sentirão mobilizados a participar.

\section{Notas}

* Este artigo apresenta pontos discutidos nas dissertações de mestrado das autoras.

${ }^{1}$ Mestranda em Ciências da Educação - Formação Pessoal e Social, Departamento de Ciências da Educação, Universidade de Aveiro, Portugal, saralucia@ua.pt.

${ }^{2}$ Mestre em Ciências da Educação - Formação Pessoal e Social, Universidade de Aveiro. Doutoranda em Ciências da Educação, Programa Doutoral em Ciências da Educação, Faculdade de Psicologia e Ciências da Educação, Universidade do Porto, Portugal, marcia.andreiat@ua.pt.

${ }^{3}$ Segundo Soares, a participação é uma atividade espontânea, que etimologicamente é a ação de fazer parte, tomar parte em, é também falar de um conceito multidimensional "que faz depender tal acção ou tomar parte, de variáveis como o contexto onde se desenvolve, as circunstâncias que o afectam, as competências de quem o exerce ou ainda as relações de poder que o influenciam" (2005, p. 116).

\section{Referências}

BRICKMAN, Nancy; TAYLOR, Lynn. Aprendizagem activa: ideias para o apoio às primeiras aprendizagens. Lisboa: Fundação Calouste Gulbenkian, 1991.

BRONFENBRENNER, Urie. The ecology of human development: experiments by nature and design. Cambridge, Massachussetts: Harvard University Press, 1979. 
BRONFENBRENNER, Urie. A ecologia do desenvolvimento humano: experimentos naturais e planejados. Porto Alegre: Artes Médicas, 1996.

DAVIES, Don; MARQUES, Ramiro; SILVA, Pedro. Os Professores e as Famílias: a colaboração possível. Lisboa: Livros Horizonte, 1993.

FONTAO, Maria del Pilar González. Modalidades de trabalho com pais na pré-escola. In: CORREIA, Luís de Miranda e SERRANO, Ana Maria (Orgs.). Envolvimento Parental em Intervenção Precoce. Porto: Porto Editora, p.165-190, 2000.

HOMEM, Maria L. O Jardim de infância e a família: fronteiras de cooperação. Lisboa: Instituto de Inovação Educacional, 2002.

KATZ, Lilian, CHARD, Sylvia. A abordagem de projecto na educação de infância. Lisboa: Fundação Calouste Gulbenkian, 1997.

MARQUES, Ramiro. Professores, famílias e projecto educativo. Porto: Edições Asa, 1998.

SPODEK, Bernard (Org.), Manual de investigação em Educação de Infância. Lisboa: Fundação Calouste Gulbenkian, 2002.

PORTUGAL, Gabriela. Ecologia do desenvolvimento humano em Bronfenbrenner. Aveiro: CIDInE, 1992.

SILVA, Pedro. Escola-família, uma relação armadilhada. Interculturalidade e relações de poder. Porto: Edições Afrontamento, 2003.

SILVA, Pedro. Pais Professores: Uma Relação em que Uns São Mais Iguais que Outros? In: Educação Sociedade \& Culturas, Campinas, n. 6, p. 179-190, maio/ago. 1996. 
SARMENTO, Teresa. (Re)pensar a interacção escola-família. In: Revista Portuguesa de Educação, n. 18, p. 53-75, 2005.

SOARES, Natália, F. Infância e Direitos: Participação das Crianças nos Contextos de Vida - Representações, Práticas e Poderes. Tese de Doutoramento em Estudos da Criança - Ramo do Conhecimento em Sociologia da Infância. Braga: Universidade do Minho, 2005.

TRICHES, Márcia A. Educação infantil em Santa Catarina (Brasil) e orientações da UNESCO. Dissertação de mestrado em Ciências da Educação - Formação Pessoal e Social. Aveiro: Universidade de Aveiro, 2008.

FERREIRA, Sara, L. Envolvimento parental e práticas dos educadores na rede privada. Dissertação a apresentar para cumprimento dos requisitos necessários à obtenção do grau de Mestre em Ciências da Educação (Formação Pessoal e Social). Aveiro: Universidade de Aveiro, (s/d).

McALLISTER, Swap, S. Developing home-school partnerships. New York and London: Teachers College, 1993.

DOE, MIMI. Ten Things Teachers Want You to Know. Disponível em: http://www.veanea.org/parents/ten-things.html, acesso em Setembro 2008.

PORTUGAL, Gabriela. Contextos facilitadores do desenvolvimento: suas características. In: TAVARES, José (Ed.). Para intervir em educação. Aveiro: CIDInE, p. 233-249, 1994. 


\title{
The parental engagement in the educational institution for childhood
}

\begin{abstract}
This paper presents a reflection about the parental engagement in the educational institution. The relation between the institute for childhood education and the family is analyzed focusing on advantages and constraints, work modalities, educational competencies and strategies for the family involvement. The requirements for this relation to be a factor of development of children, institutes for childhood education and families also are identified from the literature.
\end{abstract}

Keywords: Parental engagement, institute for childhood education, children

Recebido em: 06/05/2009

Aceito em: 16/06/2009 
